\title{
Atmospheric Corrosion Behaviour and Degradation of High- Strength Bolt in Marine and Industrial Atmosphere Environments
}

\author{
Xiaokui Yang ${ }^{1,2}$, Lunwu Zhang ${ }^{1,2, *}$, Shiyan Zhang ${ }^{1,2}$, Kun Zhou ${ }^{1,2}$, Ming Li ${ }^{3}$, Qiongyao He ${ }^{1,2}$, \\ Jingcheng Wang ${ }^{1,2}$, Shuai Wu ${ }^{1,2}$, Huaming Yang ${ }^{1,2}$ \\ ${ }^{1}$ Southwest Technology and Engineering Research Institute, Chongqing 400039, P. R. China \\ ${ }^{2}$ Chongqing Key Laboratory of Environmental Effect and Protection, Chongqing 400039, P. R. China \\ ${ }^{3}$ Avic China Aero-polytechnology Establishment, Beijing 100095, P. R. China \\ *E-mail: zhangsteri@yeah.net
}

doi: $10.20964 / 2021.01 .68$

Received: 18 September 2020 / Accepted: 8 November 2020 / Published: 30 November 2020

The atmospheric corrosion behaviour and properties degradation law of $1 \mathrm{Cr} 17 \mathrm{Ni} 2$ high-strength bolt exposed in marine and industrial atmosphere environments up to 36 months were investigated in virtue of scanning electron microscope (SEM), energy dispersive spectroscopy (EDS), X-ray diffractmeter (XRD), potentiodynamic polarization curve (PPC), electrochemical impedance spectroscopy (EIS), optical microscope $(\mathrm{OM})$, tensile strength test, double shear strength test and tension fatigue test. The test results showed that, compared with industrial atmosphere environment, high-strength bolt exhibited higher corrosion susceptibility in marine atmosphere environment. Lepidocrocite and goethite were the major constituents of the rust layer in two types of atmosphere environments, and chlorides and sulphates were detected in marine atmosphere environment and industrial atmosphere environment, respectively. Electrochemical corrosion analysis showed that the anti-corrosive properties of different parts were in this order: screw part $>$ thread part $>$ joint between thread and screw, resulting that the corrosion extent of the screw part was the lightest among three parts. The results of mechanical properties test indicated that the tension fatigue life decreased distinctly with the prolongation of the exposure time in two types of atmosphere environments, and the losses in tension fatigue life of $1 \mathrm{Cr} 17 \mathrm{Ni} 2$ high-strength bolt exposed in marine atmosphere environment was much larger than that of $1 \mathrm{Cr} 17 \mathrm{Ni} 2$ high-strength bolt exposed in industrial atmosphere environment. Tensile strength and double shear strength did not present visible decrease during the exposure time of 36 months.

Keywords: high-strength bolt; atmospheric corrosion; marine and industrial atmosphere environments; mechanical properties 
(C) 2021 The Authors. Published by ESG (www.electrochemsci.org). This article is an open access article distributed under the terms and conditions of the Creative Commons Attribution license (http://creativecommons.org/licenses/by/4.0/). 